\title{
Giyilebilir Duyargaların Kesin Besicilikte Büyükbaş Hayvanlara Uygulanması: Yemlenmenin Geviş Aktivitesinden Ayrıştırılması
}

\author{
Mehmet Hilal ÖZCANHAN \\ Bilgisayar Mühendisliği Bölümü, Dokuz Eylül Üniversitesi, İzmir, Türkiye \\ hozcanhan@cs.deu.edu.tr \\ (Geliş/Received: 11.04.2016; Kabul/Accepted: 17.08.2016) \\ DOI: $10.17671 / \mathrm{btd} .67279$
}

\begin{abstract}
$\ddot{O}_{z} \boldsymbol{e}$ - $\mathrm{Bu}$ çalışmada besicilik alanında büyükbaş hayvanların yemlenme aktivitesinin geviş aktivitesinden ayrımını kolaylaştırıcı bir gömülü sistem çözüm önerisi yapılmaktadır. İnsanlar için geliştirilen çözümlerden esinlenerek hazırlanan öneri hem donanım, hem de yazılım içermektedir. Çözüm yönsel ve açısal ivme ölçer sensör verilerine dayanarak yapılan hesaplamalarla, hayvanların boyun açısının belirlenmesi yöntemini önermektedir. Belirlenen boyun açısı sonucuna bakılarak birbirinden ayırt edilmesi güç olan "Yemleniyor" - "Yemlenmiyor" sınıflandırmasına varılabilecek, bilimsel bir büyükbaş hayvan yemlenme ayrımı yöntemi sunulmaktadır. Öneri donanım ve yazılımdan oluşan somut bir prototip sunmakta ve laboratuvar ortamında yapilan deneylerle desteklenmektedir. Sunulan prototip fazla enerji harcamadan sonuç üretebilen ve hareketlilik tespit sistemlerine ilave bir işlev olabilecek özelliklere sahiptir. Test sonuçları önceki çalışmalarda belirlenmiş uluslararası başarım ölçütlerini başarı ile geçmektedir. Sadece, önerilen çözümün büyükbaş hayvanlarda anlık aktivite tespiti için kullanılmasının uygun olmayacağı belirlenmiştir. Önerinin gerçek çiftlik ortamında da test edilmesi ve nihayetinde besicilik alanında bir ürün olarak sunulması için özel işletmeler nezdinde girişimler yapılmaktadır.
\end{abstract}

Anahtar Kelimeler - Accelerometre, Arduino, hayvancılık, gömülü sistemler, kesin besicilik

\section{An Application of Wearable Sensors for Cattle in Precision Dairy: Differentiation of Feeding and Rumination Activities}

\begin{abstract}
In present study, an embedded system is proposed for facilitating the differentiation of feeding from rumination activity, in dairy cows. The proposal is inspired from applications developed for humans that contain both hardware and software. The solution proposes a method for determining the neck angle obtained through the use of directional and angular acceleration data coming from two sensors. Using the obtained neck angle, a scientific method for differentiating between "Feeding" and "Ruminating" classification is presented. The proposal is supported by laboratory experiment results provided by a designed prototype, consisting of hardware and software. The prototype is a low-energy device giving effective results, which can be integrated to other activity sensors as an additional function. The experimentation results successfully pass the previously proven international performance tests. The only limitation is that the proposed solution is not recommended to be used as an instantaneous activity sensor tool. Efforts are underway to test the proposed solution in a real precision dairy farm and finally promote the outcome as a commercial product offered in the dairy market.
\end{abstract}

Keywords - Accelerometer, Arduino, livestock farming, embedded systems, precision diary 


\section{GİRIŞ (INTRODUCTION)}

Haber bültenlerinde et ve süt fiyatlarına sık s1k yer verildiği herkesçe bilinmektedir. Haberlerde genellikle tüketiciler fiyatların, üreticiler de besicilikteki maliyetlerin yüksekliğinden şikâyet etmektedirler. Aynı sonuç-sebep tekrarı sürekli önümüze çıkmaktadır. Besi hayvanlarının yetiştirme maliyetlerinin yüksekliği öne sürülerek, tüketiciye yansıyan katlamalı fiyatların bunun sonucu olduğu açıklanmaktadır. Haber sonunda da fiyatların tüketiciler lehine nasıl değiştirilebileceği konusunda önerilerde bulunulmaktadır. Ancak aynı döngü yıllardır sürekli tekrar etmektedir. Toplumdaki çoğunluğu mutsuz eden bu olguya çare olarak akla gelen en mantıklı çözüm besicilikteki giderlerin ve kayıpların düşürülmesidir. $\mathrm{Bu}$ amaçla günümüzde kesin besicilik (precision dairy) adı altında modern yöntemlerle besicilik yapılmaktadır [1]. Akademik çevreler kesin besiciliğin ortaya çıkma sebebini artan sürü nüfus sayısına, hayvan başı üretimin artırılması gerekliliğine ve özellikle yem fiyatlarının yükselmesine bağlamaktadır. Her bir hayvanın ekonomik değerinin artması ve modern teknolojinin hayvancılık alanında daha yaygın olarak kullanılmas ihtiyac1, kesin besiciliğe yönelmenin diğer etkenleri olarak sayılmaktadır. Her bir hayvana ait biyolojik bilgilerin modern teknoloji kullanılarak otomatik biçimde toplanıp kaydedilmesinin hayvanın sağlı̆̆ı, ihtiyaçları ve et-süt üretimi hakkında daha iyi karar verme mekanizmaları oluşturacağına inanılmaktadır. Kesin besicilikte günümüzün popüler araçları bilgisayar donanımları ve yazılımları kullanılmaktadır. Bir faaliyete bilgisayarların dâhil olması ve faaliyet sırasında yoğun olarak bilgi işlenmesi, o faaliyetin bilimsel bir çalışma alanına dönüştüğüne işaret etmektedir. Kesin besicilik de bu özelliği ile geçmiş klasik besicilikten ayrılmaktadır. Kesin besicilik tanımındaki kesin ön eki, her bir hayvanın içinde bulunduğu durum hakkında her an kesin bilgilere sahip olmak anlamında kullanılmaktadır. Diğer bir deyişle, kesin besicilik klasik hayvancılıktaki süt veren hayvanların başıboş bırakılmaları uygulamasının terk edilmesini ve sürekli gözlemlenerek içinde bulundukları fiziki durumdan anlamlar çıkartılmasını önermektedir [1], [2]. Kısaca, kesin besicilik büyükbaş hayvanların davranışlarının yakinen takibini, takipten elde edilen verilerle hayvanların sağlık ve ihtiyaç durumlarıyla ilgili çıkarımlarda bulunulmasını; böylece olası olumsuz sağlık gelişmelerinin önceden haber alınarak kayıpların önlemesini hedeflemektir. Örneğin, buzağılamadan sonra yavrulayan ineklerde oluşan ketozis, abomasum kayması veya ateş erken tespit edilerek, hayvanın "devre dışı" kalma süresi asgariye indirilebilmektedir.

Teşhis ve tanı dışında kesin besiciliğin diğer bir hedefi de sürü yönetimidir. Bilgisayarlarda depolanan kesin ve güncel verilerle kararlar almak ve alınan kararları uygulayıp sonuçlarını gözlemlemek besicilikle uğraşanlar için önemli bir yönetim kolaylığı sağlamaktadır. Kesin besicilikte sadece bilgisayarlar değil modern teknolojinin son harikaları duyargaların (sensörler) da yaygın olarak kullanımı önerilmektedir. Bir kesin besicilik sistem kurgusunda sensörler vasitasıyla veriler elde edilmekte, elde edilen veriler toplanmakta ve bir bilgi işlem modeli ile yorumlanmaktadir. Yorumlarla bir karar verme mekanizması işletilmekte, alınan kararlar besiciler tarafından uygulanmakta ve sonuçları yine sensörlerle izlenerek geri beslemelerle döngü tamamlanmaktadır. Uğraşıların temel hedefi hayvanların hastalanmasının önlenerek et ve süt veriminin artırılmasıdır. Doğal olarak, önerilen çözümlerdeki amaç besi hayvanlarının et ve süt veriminin azamiye çıkartılmasıdır. Sağlığı azami oranda iyi olan hayvanların süt verimi de azami miktarlarda seyretmektedir. Yurt dışında uzun zamandır uygulanan kesin besicilik, yurdumuzda da yaygınlaşmaktadır. Bu konuda sektörde faaliyet gösterenlere birçok yerli ve yabancı ticari ürünler sunulmaktadır. Daha erken başlamış olmanın avantajıyla, sunulan çözümler içerisinde yabancı menşeli çözümlerin çoğunlukta olduğu görülmektedir. Çözümlerde kullanılan donanımların da teknolojideki gelişmelere paralel olarak değişmekte ve gelişmekte olduğu izlenmektedir. En fazla kesin besicilik çözüm ürünü, hayvancılığın en çok gelişmiş olduğu ülkeler olan İsviçre, Hollanda, İsveç, Almanya, A.B.D. ve Fransa'dan gelmektedir. Ancak, komple bir çözümü olmayan sadece kısmi çözümler sunan diğer bazı ürünler de Avrupa ülkelerinden ithal edilmektedir.

İthal edilen çözümler bir besi çiftliğindeki hayvanların radyo frekanslı kimlik tanıma (RFID: Radio Frequency Identification) teknolojisiyle, otomatik olarak belirli bir mesafeden tanınmasıyla başlamıştır. Otomatik kimlik tanıma ve kimlik onayı birçok pratik uygulamada yer bulmaktadır. Öncelikle, RFID birçok hayvanın bir arada bulunduğu ortamlarda hızlı bir şekilde hayvanların ayırt edilmesinde kullanılmaktadır. Örneğin, bir hayvanın kimliği birkaç metre mesafeden tespit edilerek bir bilgisayar kontrol yazılımına aktarılmaktadır. Yazılım yayınladığı komutlarla istenen kapıyı otomatik olarak açmakta ve kimliği onaylanan hayvan önceden belirlenen alana yönlendirmektedir. Yöntemin temelinde, hayvanın boynuna asılan korumalı plastik bir kutu içerisindeki özel bir seri numarasına sahip elektronik RFID etiketi (tag) yer almaktadır. Tag, okuyucusu tarafindan oluşturulan elektromanyetik alan etkisi ile enerjilendirilmekte ve içerisindeki yegâne kimlik numarası okunmaktadır.

RFID uygulamalarının yaygınlaşması esnasında, mikrodenetleyici teknolojisinde gelişmeler kat edilmiş ve entegre boyutları daha da küçülürken, içerdikleri çekirdek sayısı artmıştır. $\mathrm{Bu}$ gelişmeler üzerine elektronik sensörlerin de boyutlarının küçüldüğü, insanlar üzerine takılan giyilebilir sensör uygulamalarının arttı̆̆ izlenmiştir. Daha sonra, giyilebilir sensör uygulamalarının hayvanlar üzerindeki uygulamalara da yayıldığı gözlemlenmiştir. Süt verimini büyük ölçüde etkileyen kızgınlık, topallık, sakatlık tespiti ve geviş sayımı ilk hedeflenen uygulama alanları olmuştur. Örneğin, hayvanlarda kızgınlık tespiti için boyun kısmının sol 
tarafına konumlandırılan tasma şeklinde sensörler önerilmektedir [1-3]. Bu sensörler hayvanın hareketlilik verilerini takip etmekte ve hayvanın kızgınlığa girip girmediğine karar vererek çiftlik yetkililerini uyarmaktadır [3]. Büyükbaş hayvanlarda geviş getirme diğer bir doğal özelliktir. Geviș getirme ön mideye alınan saman veya ot türündeki yemin ağıza geri getirilerek, yeniden çiğnenip öğütülmüş hale getirilmesine denmektedir. Geviş, yemin hazmını kolaylaştırmaktadır. Geviş getirme anını gösteren bir enstantane Şekil 1'de görülmektedir. Şekilde hayvan alt çenesinin ağızdaki yemi ögütmek için bir değirmen gibi yana kayarak çalıştığ 1 açıkça görülmektedir. Her yetişkin süt ineğinin bir günde ortalama 450-500 geviş getirmesi normal sağlık göstergesi olarak kabul edilmektedir [2]. Geviş ortalamasındaki bir düşüş gebelik, sağlık sorunu veya normal dişı biyolojik bir gelişme olarak kabul edilmektedir [1]. Görüldüğü gibi geviş sayımı kesin besicilikte bir ön uyarı göstergesi görevi görmektedir.

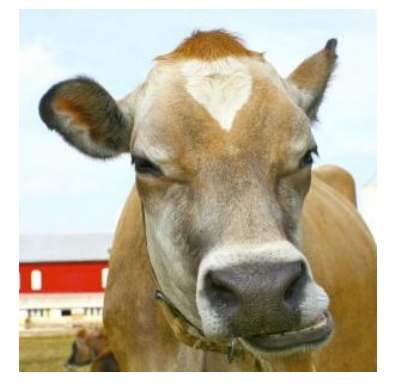

Şekil 1. Büyükbaş hayvanlarda geviş aktivitesi (Rumination activity in cattle)

Geviş sayımı takibinin en basit yöntemi, hayvanların izlenerek çenenin öğütücü biçiminde çalıştığı sürelerin not alınmasıdır. Ancak, hareketli bir padokta takip edilecek hayvan sayısı arttıkça bu yöntem pratik olmaktan çıkmaktadır. Dolayısıyla, hayvanların geviş sayımlarının hareketlerinden ve bulundukları noktadan bağımsız olarak, takılacak bir aparatla düzenli ve hatasız yapılmas önemli bir ihtiyaçtır. Geviş sırasında burun bölgesinde meydana gelen gerilmeler ve gevşemeler, geviş sayımında en çok kullanılan özelliktir. Buruna takılan esnek aparatlar sayesinde, basınç ve elektronik anahtar değişimleri izlenerek geviş sayımı yapılmaktadır. Son olarak geviş esnasında hayvanın çıkardığı seslerin akustik biotelemetriyle çözümlenmesi yöntemi geliştirilmiştir [2], [4-6]. Şekil 2'de geviş sayımı için hayvanların burun ve boyun bölgesine takılan aksesuarlar görülmektedir. Ancak, takılan aksesuarların sayısının artması ve ebatlarının büyümesi hayvanları rahatsız edebilmektedir.

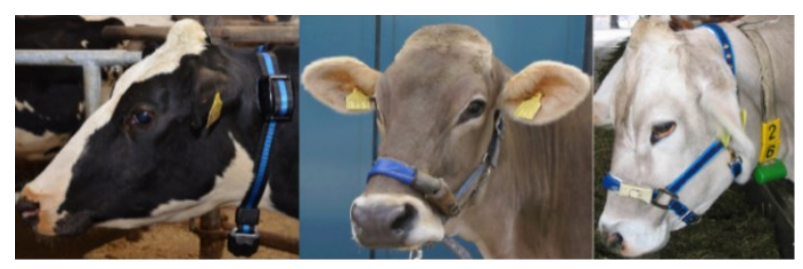

Şekil 2. Geviş sayımı için kullanılan aksesuvar örnekleri (Accessory samples for rumination count)
Kesin besicilikte, hayvanların yemlenme sıklığı ve süresi takip edilen diğer bir sağlık göstergesi sayılmaktadır. Yeterli ve düzenli beslenmenin süt veriminde önemli bir rol oynadığı bilinmektedir. Klasik yöntemdeki gibi, zamanı geldiğinde hayvanların önüne aynı ölçekte yem konması artık eskide kalmıștır. Şimdilerde hedef, her bir hayvandan azami süt miktarını elde etmek için, her hayvana özel yem miktarı, verilme zamanı ve sıklığının belirlenmesidir. $\mathrm{Bu}$ konuda da, geviş takibine benzer yöntemler kullanılmaktadır. Ancak, yemlenme ve geviș fiziksel olgu olarak birbirine benzediğinden, gözlem dışı ayrım yöntemlerinde sıkıntılar yaşanmaktadır. En önemli sorun geviş ile yemlenmenin net bir biçimde ayrıştırılması için kullanılan yöntemlerin maliyeti, hata oranları ve gerçek yaşamda uygulanabilirliğinde ortaya çıkmaktadır. Sunulan çalışmanın amacı ayrımı en pratik şekilde gerçekleştiren bir çözüme ulaşmaktır.

\section{BENZER ÇALIŞMALAR (RELATED WORK)}

Büyükbaş hayvanlardaki kızgınlık, yemlenme ve geviş alışkanlıklarının takibinin hayvan sağlığı ve verimine olan etkileri kesin besicilik çalışmalarının temelini oluşturmaktadır [6-9]. Küçük ve büyükbaş hayvanların yemlenme ve geviş aktivitelerinin takibi yapılarak sağlık durumlarındaki gelişmelerden erken uyarılar alma konusunda 1958 yılından beri çalışmalar yapılmaktadır [5]. Yemleme ve geviş takibi için genelde çene hareketlerine bağlı kas gerilme ve seslerinin doğurduğu enerji boşalmalarının analizi kullanılmaktadır [6]. Buruna takılan esnek aparatlarla çene kaslarının genişleyip daralmasına bağlı olarak ortaya çıkan basınç değişimleri, deformasyondan kaynaklanan kapasitans değişimleri ve elektronik anahtarların açılıp-kapanması kullanılarak yemlenme takibi ve geviş sayımı gerçekleştirilmektedir [6]. Geviş ve yemlenme esnasında hayvanın çıkardı ğ farklı seslerin akustik biotelemetriyle çözümlenmesi ise yeni bir yöntem olarak tanımlanmaktadır. Boyutları küçülen ve ucuzlayan sensörlerle birlikte, çalışmalar verilerin otomatik olarak sürekli olarak toplanmasına yönelmiştir. Kesin besicilikte evrimleşme toplanan verilerin saklanması-işlenmesi-yorumlanması, uyarılar üretilmesi, kararlar alınması işlemlerinin otomasyona sokulması süreçleriyle devam etmiştir. Son aşama olarak mobil cihazlara (tablet ve cep telefonları) anlık bilgi gönderilmesine başlanmıştır.

Kesin besicilikte kullanılan ticari çözümler ve yapılan bilimsel öneriler birçok güncel yayında incelenmekte ve değerlendirilmektedir. Geviş süresini ölçen ticari bir çözüm çalışma [1]'de incelenmiş ve yapılan tespitlerinin doğruluğu değerlendirilmiştir. Çalışma [2]'de kızgınlık tespit sensörleri için kullanılan tasmalara, geviş tespit sensörlerin eklendiği çözüm değerlendirilmektedir. 1972 yılından beri büyükbaş hayvanların çene hareketleri tespiti, sınıflandırması ve değerlendirmesini yapan 
çalışmalar da incelenmiştir [4]. İncelenen çalışmalarda yemlenme aktivitesindeki parçalama ve geviş aktivitesindeki ögütme hareketlerindeki farklılıklar ortaya konmuştur. Aktivitelerde çıkan seslerde de farklılık olduğu, bu sayede yemlenme ile gevişin ayrıştırılabildiği anlaşılmıştır. Ancak, ses analizi ile yapılan testlerin sonuçlarında \%22'ye varan hata payı olduğu vurgulanmaktadır. Bazı ineklerde geviş zamanının gerçek süreden devamlı daha az tespit edildiği, bazılarında ise devamlı doğru tespit edildiği görülmüştür. Farklı cinsiyet ve farklı yaşlardaki hayvanların yemlenme, çiğneme hareket alışkanlıklarının da farklı olmasından dolayı, ses analizi sensörlerinin her hayvana özel kalibre edilmesi gerektiği anlaşılmıştır. Aynı ürünün kimlik tespiti için kullanılan başka bir ticari ürünle birlikte çalıştırıldığında olumsuz etkilendiği belirtilmektedir. Sonuç olarak, incelenen ticari akustik biyotelemetri sensörünün doğru geviş tespiti yaptığının tam güvenle söylenmesinin mümkün olmadığı beyan edilmektedir. [4]. Diğer bir çalışmada, her hayvan için önceden tayin edilen ferdi eşiklere göre çalışan bir geviş ve yemlenme takip sistemi önerilmektedir [6]. Ancak değişik ırkların farklı kafa yapıları ve boyutları olmasından dolayı bu yöntem her büyükbaş hayvana takılacak sensörünün özel olarak ayarlanmasını gerektirmektedir. Bu dezavantaja ilaveten, takılan aparatın hayvanın yemlenmesini olumsuz yönde etkileyebileceğini ifade edilmektedir. Aynı çalışmada farklı yöntemlerle yapılan ölçümler bir tabloda mukayese edilerek, yöntemlerin hiçbirinin tüm kıstasları tatmin edici sonuçlar verdiğinin saptanamadığı açıklanmaktadır. Farklı bir çalışmada ise basınç yöntemiyle akustik biyotelemetri yöntemi karşılaştırılmaktadır. Sonuç olarak her iki yöntemin de gözlemle yapılan ölçümlere göre daha az değerler verdikleri açıklanmaktadır [10]. Çalışma [5]'te akustik biyotelemetriye dayalı yöntemlerde hataya sebep olan nedenler incelenmektedir. Hayvan yaşına, günün aydınlık saatlerine, her hayvanın kendine has yapısına bağlı olarak ses frekanslarında da farklılıklar oluştuğu anlatılmakta, hatalar bu sebebe bağlanmaktadır. Görüldüğü gibi pahalı çözümler, karmaşık analizler ve incelikli yöntemlere rağmen yemlenme ve geviş aktivitelerinin takibi ve ayrımı halen tatmin edici şekilde gerçekleştirilememektedir.

\section{3. ÖNERILLEN ÇÖZÜM (PROPOSED SOLUTION)}

\subsection{Motivasyon (Motivation)}

Ülkemizde besicilik çiftliklerinde hayvan aktivitelerinin takibinin yapılması, otomasyondaki yüksek maliyetperformans oranları gerekçesiyle tercih edilmemektedir. Önerilen çözümlerin maliyetlerinin düşük olması, hem de hayvanların yaşam konforunun bozulmaması koşul olarak önümüze gelmektedir. Bu koşullar otomatik veri toplama ve işlemenin ucuz yöntemlerle gerçekleştirilmesini gerektirmektedir [4], [6]. Modern teknoloji araçlarının büyükbaş hayvanların çiğneme aktivitelerinin analizini yapabilme kapasitesine sahip oldukları kanıtlanmış, fakat ülkemiz için pahalı sayıldıkları anlaşıılmıştır [6]. Öte yandan, insanlar için yapılan sensörlerin başarılı sonuçlar verdiği ve çok pahalı olmadıkları da bilinmektedir [11], [12]. Çalışmamızın motivasyonunu da bu iki gerçeği bir araya getirmek oluşturmaktadır. İnsan vücut duruşlarının tespitinde kullanılan bir yöntemin uyarlama yapılarak, hayvanlara uygulanması amaçlanmıştır. Amaçlandığı gibi önerilen yöntem önceki önerilerin altında maliyet getiren, uygulanan hayvanlara rahatsılik vermeyen bir uygulamadan oluşmaktadır.

\section{2. Önerilen Gömülü Sistem (Proposed Embedded System)}

Önerilen düzenekte, içerisinde iki adet sensörü barındıran ve insanlarla ilgili uygulamalarda da yer alan popüler bir veri toplama donanımı kullanılmaktadır. $\mathrm{Bu}$ donanım üzerinde bir adet yönsel (directional), bir adet de açısal (angular) olmak üzere, iki adet hılanma (ivme) sensörü bulunan popüler MPU6050 kartıdır. Kart üç düzlemdeki $\left(\mathrm{a}_{\mathrm{x}}, \mathrm{a}_{\mathrm{y}}, \mathrm{a}_{\mathrm{z}}\right)$ hızlanmaları algılayarak yönsel hareketleri; üç düzlemdeki $\left(\mathrm{w}_{\mathrm{x}}, \mathrm{w}_{\mathrm{y}}, \mathrm{w}_{\mathrm{z}}\right)$ açı hızlanmalarını algılayarak açısal değişiklikleri tespit edebilmektedir. Kartın GY521 modeli Arduino uygulama geliștirme platformu kartlarına kolayca takılarak çalıştırılabilmektedir. Arduino, donanım ve yazılım kütüphaneleri açık erişime sahip birçok akademik çalışmada kullanılan, popüler bir eğitim platformudur. Çalışmamızın geliştirme aşamasında, Arduino Nano kartı üzerine bir MPU 6050 kart1, bir de Bluetooth iletişim kartı takılmıştır. Tasarımın blok şeması Şekil 3'te görülmektedir. Toplanan yönsel ve açısal ivmeler boyun açısı hesaplamakta kullanılmaktadır. Hesaplama sonucunda elde edilen açı değeri Bluetooth kartı vasıtasıyla mobil cihaza iletilmektedir. Aslında, tasarımımızın farklı iletişim yöntemi kullanan değişik uyarlamaları insanlarla ilgili uygulamalarda kullanılmaktadır. Örneğin, ivme ölçer kullanarak insanların oturma pozisyonundan ayağa kalkma ve ayakta pozisyonundan oturma pozisyonuna geçiş durumlarının tespiti yapılmıştır [11]. İkinci bir örnekte, hastaların yataklarından kalkma ve yeniden dönme anlarının tespiti önerilmiştir [12]. Çalışmalarda yönsel ve açısal hızlanmalar kısa aralıklarla örneklenerek, vücut duruş açısının hesaplanmaktadır. Tespit edilen vücut açısından da farklı çıkarımlarda bulunulmaktadır. Yere düşen hastadan anında haberdar olunması, refakatçisiz yataktan kalkan hastaların düşmelerini önleyici tedbirler alınması gibi uygulamalar çalışmalara örnek teşkil etmektedir [13].

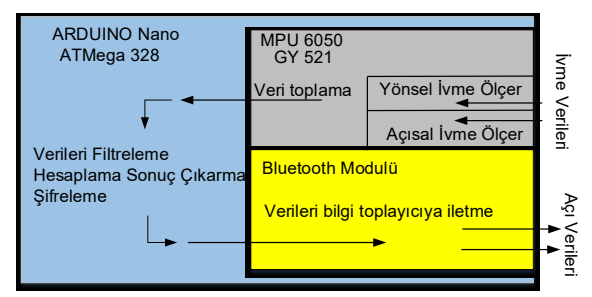

Şekil 3. Önerilen tasarımın blok şeması (Block diagram of proposed design) 
İnsanlarla ilgili uygulamalardan esinlenerek büyükbaş hayvanların boyun duruş şeklinin tespit edilmesinin mümkün olduğu açıkça anlaşılmaktadır. Büyükbaş hayvanların barınak ve açık alanlarda yemlenir konumda iken, boyunlarının aşağıya doğru duruşu Şekil 4'teki resimlerde görüntülenmektedir. Yemlenme duruşundaki aşağıya doğru eğilmiş boyunların yatay düzleme göre yaklaşık $45^{\circ}$ açı (boyun açısı) yaptığı izlenmektedir. Oysa geviş ve etrafa bakınma duruşlarındaki (Şekil 1,2) boyun açılarının yemlenme duruşundaki açıdan çok farklı olduğu görülmektedir. Dolayısıyla, boyun açısı kullanılarak yemlenmenin geviş aktivitesinden ayrıştırılması, bu çalışmanın temel yöntemi olarak belirlenmiştir.
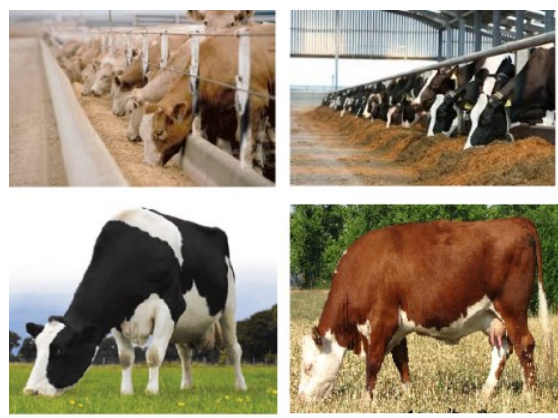

Şekil 4. Yemlenme sırasında boyun duruş şekilleri (Neck posture of cattle while feeding)

Boyun açısının ölçülmesi için Şekil 5'de görülen tasarım yapılmıştır. Tasarım Arduino platformunun kullandığ ATMega 328 mikro-denetleyici ve ona bağl1 MPU 6050 kartı ile Bluetooth modulü kullanılarak gerçekleştirilmiştir. Elde edilen Büyükbaş Hayvan Boyun Açısı Tespit Sensörü (BHBATS) laboratuvar ortamında test edilerek doğruluk, hassasiyet, özgüllük ve hata oranı performansı parametreleri hesaplanmıştır. Donanım enerji olarak tablet bilgisayar pili ile beslenmekte ve yaklaşık dört saat süreyle boyun açısı tespiti yapabilmektedir.

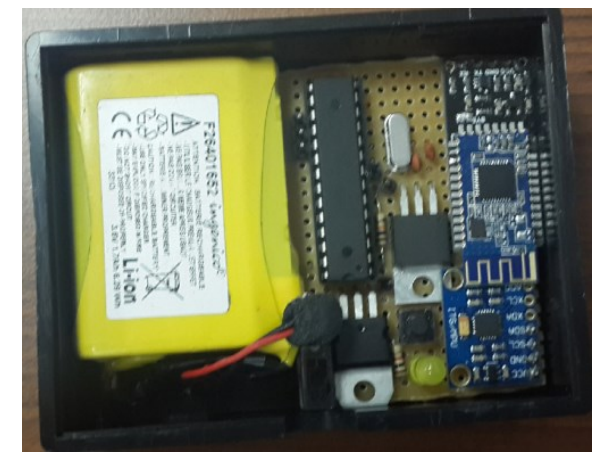

Şekil 5. Tasarımı yapılan donanım prototipi (Prototype of designed hardware)

Boyun açısı iki sensörün verilerinin de kullanıldığı bir yöntemle elde edilmektedir. Önce üç boyuttaki yönsel ivme değerlerinden denklem (1) kullanılarak yönsel ivmelerin karelerinin toplamlarının karekökü hesaplanmaktadır (RSS, root sum of squares) [14]. Daha sonra üç boyuttaki açısal ivme değerlerinden denklem (2) kullanılarak açısal ivmelerin karelerinin toplamlarının karekökü hesaplanmaktadır $\left(\mathrm{w}_{\mathrm{R}}\right)$. $\mathrm{Bu}$ iki değer elde edildikten sonra tümleyici filtreleme kullanılarak boyun açısı (Açı) denklem (3) ile elde edilmektedir [15].

$$
\begin{gathered}
R S S=\sqrt{a_{x}^{2}+a_{y}^{2}+\mathrm{a}_{z}^{2}} \\
w_{R}=\sqrt{w_{x}^{2}+w_{y}^{2}+\mathrm{w}_{z}^{2}} \\
\mathbf{A c ̧ ı l}=0.98 \times\left(\Theta+w_{R} \times \mathrm{t}\right)+0.02 \times R S S
\end{gathered}
$$

$\Theta=$ mevcut açı, $\mathrm{t}=$ örnekleme süresi.

Filtreleme, küçük yer değişimlerinden bile çok etkilenen yönsel hızlanmaların hesaplamalardaki ağırlığının azaltılması, örnekleme süresine göre hesaplanan açısal ivme değerlerinin de hesaplamalardaki ağırlığının artırılması amaciyla yapılmaktadır. Filtreleme elde edilen Açı değerinin gözlemlenen anlık değere göre daha doğru ve daha tutarlı olmasını sağlamaktadır [15]. Üç adet denklemden oluşan hesaplamalar mikro-denetleyiciyi yormadan, dolayısıyla fazla enerji tüketimine sebep olmadan gerçekleştirilmektedir. Ayrıca, BHBATS'ın sürekli örnekleme yapması gerekmemektedir; çünkü büyükbaş hayvanlar genellikle ağır hareket ettiklerinden, boyun açıları sürekli anlık değişim göstermemektedir. Üç saniye aralıklarla örnekleme alıp boyun açısını hesaplamak gözlemlenen açıyla aynı sonuçlar üretilmesinde yeterli olmaktadır. En çok enerji, hesaplama sonucu bulunan açı değerinin Bluetooh modülü tarafından iletimi sırasında, haberleşme protokolunun gerekleri yerine getirilirken sarf edilmektedir. Bu sarfiyat da Açı değerlerinin üç tur toplanarak, dokuz saniyede bir gönderilmesi yoluyla en aza indirilmeye çalışılmıştır. Her yeni MCU 6050 kartının kullanılmadan önce yere paralel duruş konumunda yatay düzleme yaptığı açı dikkate alınmalıdır. Aslında, ideal koşullarda sıfır olması gereken bu değer, imalat hatalarından dolayı sıfır olmamakta ve hesaplamalarda düzeltme değeri olarak kullanılmaktadır. $\mathrm{Bu}$ kalibrasyon gerçekleştirilmediği takdirde ölçülen açı değerleri hatalı tespit edilmekte ve yanlış tahmin veya kararlara sebep olmaktadır.

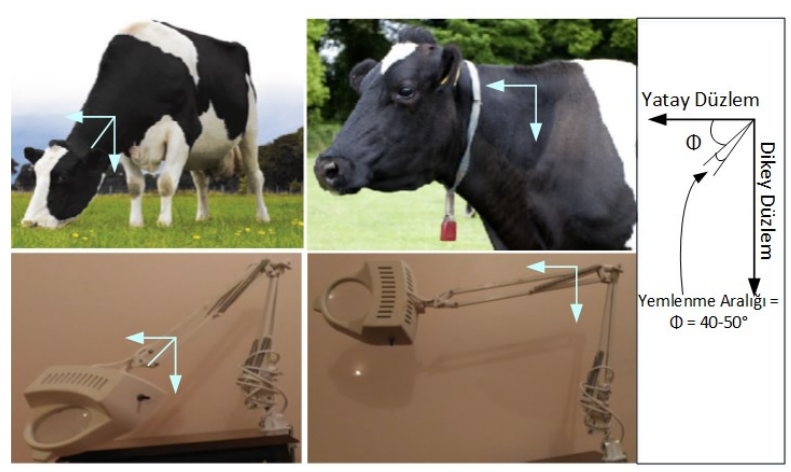

Şekil 6. Boyun açısı ve benzetimi (Neck angle and its representation) 
Şekil 6'da da ğörüldüğü gibi üç noktada oynar bir masa lambası, bir ineğin boyun duruş şekilleri ile benzeştirilebilmektedir. Lamba düzeneğinin masaya tutunan kol kısmı hayvan ön ayağına, ortadaki kol kısmı hayvanın boyun kısmına, oynar başlık da hayvanın kafasına benzetilerek deneyler yapılmıştır. Deneyler, rastgele konumlara alınan masa lambasının süre tutularak yatayla yaptığı açının (Şekil 6'daki $\varnothing$ açısı) $10 \mathrm{kez}$ elde edilmesiyle gerçekleştirilmiştir. Aynı deneyler 100 farklı konumda tekrarlanarak, toplamda $\varnothing$ değeri süreye karş1 $1000 \mathrm{kez}$ tespit edilmiştir. Deneylerin 10 tanesinde, lamba kolunun konumu değiştirilme sürecinde iken açı değeri hesaplanmıştır. Bu deneylerle, hayvanın beklenmedik bir şekilde kafasını yukarıya kaldırması veya yemlenmek için aşağıya doğru indirmesi canlandırılmıştır. Bluetooth iletişimiyle açı değeri mobil cihazlara - hem tablet bilgisayar hem de akıllı telefona - iletilmiştir. Mobil cihazlarda koşan bir yazılım, Şekil 6'daki $\varnothing=40-50^{\circ}$ lik açı aralığını "Yemleniyor" olarak sınıflandırmakta ve bu açı aralığında geçen süreleri birbirine ekleyerek yemlenme süresini saniye cinsinden bulmaktadır. Dolayısıyla, deney sonuçları ile sadece boyun açı değeri saptanmamakta, aynı zamanda belirli bir boyun açısı değerinin süresi de değerlendirmeye alınmaktadır. Önerilen çözüm, değerlendirilen süre içerisinde "Yemleniyor" veya "Yemlenmiyor" sinıflandırma tahmini ortaya koymaktadir.

\subsection{Katkılarımız (Contribution)}

Yapılan çalışma ile daha önce karmaşık analiz ve değerlendirme metotlarına dayalı yöntemler yerine, efektif (az enerji sarfiyatı ile aynı tespiti gerçekleştiren) bir yöntem sunulmaktadır. BHBATS tasarımı ile büyükbaş hayvanların yemlenme ve geviş getirme aktivitelerinin ayrımının yapılabilmesi çalışmalarına aşağıdaki katkılar verilmektedir.

- Üç denklemle boyun açısının hesaplanması ve sadece sonucun 3 turda bir iletiminin yapılması,

- Tek yerine çift sensör verisine dayalı birbirini destekleyen verilerle sonuç alınması,

- Önceki çalışmalara göre az enerji tüketen, ucuz bir yöntem sunulması.

Aslında, BHBATS'nün kendi başına çalışan bir donanım olması gerekmemektedir. Hali hazırda, bazı hayvanlarda yönsel ve açısal ivme ölçer sensörlerle hareketlilik ve adımlama tespiti yapılmaktadır. Mevcut donanımların gömülü sistem yazılımlarında tadilat yapılarak, önerilen yöntemin ilave edilmesiyle, yemlenme-geviş ayrımı özelliğin elde edilmesi mümkün olmaktadır. Diğer bir deyişle, BHBATS mutlaka ilave bir donanım maliyeti getirmemektedir. Çalışmamız bu yönüyle de diğer çözümlerden ayrılmakta ve kesin besicilik alanına, asgari yatırımla ilave işlevsellik kazandırma katkısında bulunmaktadir.

\section{TEST SONUÇLARI VE DEĞERLENDİRME (TEST RESULTS and EVALUATION)}

Yapılan testlerde, belirlenen örnekleme ve sonuç iletimi zamanlamasının yeterli olduğu, daha sık örnekleme veya sonuç iletiminin "Yemleniyor-Yemlenmiyor" kararına etkisi olmadığı anlaşılmıştır. Dolayısıyla, daha fazla örnekleme ve daha sık sonuç iletimine gidilmeyerek, enerji tasarrufuna dikkat edilmiştir. Yapılan toplam 1000 deneyin 10 tanesinde, kullanılan düzenek hareket halindeyken sonuç alınmış ve değerlendirme yapılmıştır. Diğer 990 deneyde düzenek sabit halde iken ölçüm alınmıştır. Deney sonuçları Doğru Pozitif (DP), Hatalı Pozitif (HP), Doğru Negatif (DN) ve Hatalı Negatif (HN) olarak sınıflandırılmıştır. Daha sonra her deney sonucu dört sınıftan birisine skor olarak girilmiştir. DP, HP, DN ve HN sınıflandırmasının yemlenme tespit deneyleri için istatistiki anlamı aşağıdaki şekilde belirlenmiştir:

DP: Boyun açısının 40-50 olduğu bulunup BHBATS'nün doğru olarak "Yemleniyor" tespit sayısıdır.

HP: Boyun açısı 40-50 olmamasına rağmen BHBATS'nün hatalı olarak "Yemleniyor" tespit sayısıdır.

DN: Boyun açısı 40-50 olmamasından dolayı BHBATS'nün doğru olarak "Yemleniyor" tespiti yapmama sayısıdır.

HN: Boyun açısı 40-50 olmasına rağmen BHBATS'nün hatalı olarak "Yemleniyor" tespiti yapamama sayısıdır.

İnsanlarla ilgili aktivite ve duruş şekli tespiti çalışmalarında, tespitlerdeki başarım yukarıda belirlenen istatistiki sonuçlar kullanılarak dört ölçütle değerlendirilmektedir [11], [13]. $\mathrm{Bu}$ çalışmada da kullanılan başarım ölçütleri şunlardır:

1. Doğruluk: Aktiviteleri ("Yemleniyor" "Yemlenmiyor") doğru tespit etme.

$$
\text { Doğruluk }=\frac{\mathrm{DP}+\mathrm{DN}}{\mathrm{DP}+\mathrm{HP}+\mathrm{HN}+\mathrm{DN}} \times 100
$$

2. Hassasiyet: Takip edilen aktiviteyi ("Yemleniyor") doğru tespit edebilme kabiliyeti.

$$
\text { Hassasiyet }=\frac{\mathrm{DP}}{\mathrm{DP}+\mathrm{HN}} \times 100
$$

3. Özgüllük: Takip edilen aktiviteyi hatalı tespitlerde bulunmama kabiliyeti.

$$
\text { Özgüllük }=\frac{\mathrm{DN}}{\mathrm{DN}+\mathrm{HP}} \times 100
$$

4. Simetrik ortalama hata oranı (SMAPE: Symmetric Mean Average Percentage Error).

$$
H a t a=\frac{\text { (ölçülen değer }- \text { gerçek değer })}{(\text { ölçülen değer }+ \text { gerçek değer }) / 2} \times 100
$$


Tablo 1'de, deneylerde alınan sonuçlar verilmektedir. Yapilan 1000 deneyin 593 seferinde düzenek "Yemleniyor" konumuna, 397 seferinde "Yemlenmiyor" konumuna sokularak BHBATS tarafindan tespit edilen sonuçlar ve süreleri kaydedilmiştir. Örneğin, düzenek bir dakikaya yakın süreyle $80^{\circ}$ 'lik bir açıya sokulmuş ve BHBATS'nün yaptığı tespit dört sınıflandırmadan birisine kaydedilmiştir. Zaman kronometre ile açı ise iletki ile ölçülmüş, bir dakika süreyle BHBATS'nün yaptığı tespit "Yemlenmiyor" ise DN bir artırılmıştır.

Tablo 1. Deney sonuçları tablosu (Table showing test results)

\begin{tabular}{|c|c|c|c|c|}
\hline \multirow{2}{*}{ Deney } & \multicolumn{4}{|c|}{ Sayısal Sonuçlar } \\
\cline { 2 - 5 } & $D P$ & $H P$ & $D N$ & $H N$ \\
\hline $\begin{array}{c}\text { Yemlenme } \\
\text { Tespiti }\end{array}$ & 597 & 1 & 401 & 1 \\
\hline
\end{tabular}

DP değerinin bir artırıldığı tipik bir deney örneğinde ise, bir dakikaya yakın süreyle düzenek yaklaşık $45^{\circ}$ 'lik bir açıya sokulmuş ve BHBATS'nün yaptığı tespitin "Yemleniyor" olup olmadığı kontrol edilmiştir. Yapılan 10 hareketli deneyin 5 seferinde düzenek "Yemleniyor" konumundan "Yemlenmiyor" konumuna alınırken, 5 seferinde de "Yemlenmiyor" konumundan "Yemleniyor" konumuna hareket ettirilirken sonuçlar kaydedilmiştir. $\mathrm{Bu}$ deneylerin 8'inde süre bir dakika civarında, ikisinde ise 4 saniye civarında tutulmuştur. "Yemleniyor" konumundan "Yemlenmiyor" konumuna geçişleri BHBATS 3-5 saniye gecikmeyle 4 deneyde doğru tespit ettiği için, DP sayısı 4 artırılmıştır. "Yemlenmiyor" konumundan "Yemleniyor" konumuna geçişleri BHBATS 3-5 saniye gecikmeyle 4 deneyde doğru tespit ettiği için DN sayısı 4 artırılmıştır. Dolayısıyla, haraketli deneylerin sonuçlarıyla birlikte toplamda DP sayısı 597'ye, DN sayısı da 401'e ulaşmıştır (Tablo 1). Süre iki deneyde bilinçli olarak 3 saniye civarında tutulmuştur. BHBATS hem "Yemleniyor" konumundan "Yemlenmiyor" konumuna geçişi hem de "Yemlenmiyor" konumundan "Yemleniyor" konumuna geçişi 3 saniye içerisinde doğru tespit edemeyerek, bir önceki konumu verdiğinden HP ve HN sayıları birer artırılmıştır. Diğer bir deyişle tasarlanan BHBATS anlık boyun açısını takip etmekte başarılı görünmemektedir; çünkü gözlemlenen gerçek aktivite ile mobil cihaz ekranında çıkan sonuç arasında yaklaşık 5 saniyelik gecikme olmaktadır. Dolayısıyla, BHBATS ile kısa aktiviteler veya aktivite geçişlerinin takibi hedeflenmemelidir. Tasarlanan BHBATS sonuçta 593 "Yemleniyor" ve 397 "Yemlenmiyor", toplamda 990 sabit konumu doğru olarak tespit etmiştir. Bir dakikaya yayılan hareketli 8 deneyin tümünde de tanımlama doğru olarak tespit edildiğinden, genel toplamda BHBATS 1000 duruşun 998 tanesini doğru tespit etmiştir.

Çalışmamızın başarım sonuçları başarı ölçütü (4-7) denklemleri kullanılarak hesaplanmış ve Tablo 2'de verilmiştir. Sonuçlara göre düşme çalışmamızın doğruluğu \%99,80, hassasiyeti \%99,83, özgüllüğü \%99,75 olarak belirlenmiştir. \%99'un üzerindeki bu sonuçlar tasarımın başarılı olduğunu göstermektedir.
$\% 0,02$ olan hata oranı önerilen çözümün yemlenme aktivitesini hemen hemen hatasız olarak tespit ettiğini göstermektedir. Hatalı tespitlerin de hareket halindeki (konum değiştirme) anlarda yapılan tespitlerden kaynaklandığı göz önüne alındığında, uzun süreli ölçümlerde hata oranının artmayacağı anlaşılmaktadır. Büyükbaş hayvanlar ani hareketlerde bulunamayacak kadar büyük vücut boyutlarına sahiptirler ve insanlar kadar ani hareketler yapmamaktadırlar. Dolayısıyla, uzun süreli büyükbaş hayvan takiplerinde BHBATS hata oranının düşük olması beklenmelidir.

Tablo 2. Başarım Sonuçları Tablosu (Table showing performance results)

\begin{tabular}{|c|c|c|c|c|}
\hline \multirow{2}{*}{ Ölçüm } & \multicolumn{4}{|c|}{ Başarım Ölçütü } \\
\cline { 2 - 5 } & Doğruluk & Hassasiyet & Özgüllük & Hata Oranı \\
\hline Başarım & $\% 99,80$ & $\% 99,83$ & $\% 99,75$ & $\% 0,20$ \\
\hline
\end{tabular}

\section{SONUÇ (Conclusion)}

Çalışmada besicilik alanına uygulanabilecek bir gömülü sistem önerisi yapılmaktadır. Öneri, büyükbaş hayvanların yemlenme aktivitelerinin takibini ve geviş aktivitesinden ayrımını kolaylaştırıcı bir çözümü içermektedir. Sunulan çözüm insanlar için geliştirilen çözümlerden esinlenerek hazırlanmıştır. Çözüm yönsel ve açısal ivme ölçer sensör verilerine dayandırılmaktadır. Sensör verileriyle hayvan boyun açısının hesaplanmasından elde edilen sonuçlar kullanılarak, bilimsel bir yemlenme tespit yöntemi oluşturulmaktadır. Yöntem, büyükbaş hayvanların boyunlarının yemlenme esnasında yatay düzlemle yaklaşık $45^{\circ}$ 'lik bir açı, geviş getirme esnasında ise yaklaşık $90^{\circ}$ 'lik bir açı yaptığı bilgisi kullanılarak oluşturulmuştur. Yemlenme ve geviş aktivitelerinin anlık değişen aktiviteler olmamasından dolayı, 10 saniyede bir mertebesinde izleme yapmanın doğru sonuçlar verdiği anlaşılmıştır. Öneri, somut bir prototip donanım sunmakta ve prototiple yapılan deney sonuçlarıyla da desteklenmektedir. Test sonuçları önerinin bu konudaki başarım ölçütlerini başarı ile geçtiğini göstermektedir. Ancak, sonuçlar önerilen çözümün büyükbaş hayvanlarda anlık yemlenme aktivitesi tespit aracı olarak kullanılamayacağı göstermektedir.

Tasarlanan donanım ve yazılımın gerçek çiftlik ortamında hayvanlara takılarak denenmesi için girişimler yapılmaktadır. Ayrıca geliştirilen yazılımın daha görsel ve içerikli olması çalışmalarına devam edilmektedir. Diğer bir hedef de tespit süresinin kısaltılarak, düzeneğin anlık yemlenme aktivitelerini de daha kısa gecikmelerle tespit etmesinin sağlanmasıdır. Nihai hedefte ise, destek programları kapsamında ticari ürüne dönüştürülebilecek daha küçük boyutlu bir tasarımın gerçekleştirilmesi bulunmaktadır. 


\section{KAYNAKLAR (REFERENCES)}

[1] E. Maltz, "Novel Technologies: Sensors, Data and Precision Dairy Farming", The First North American Conference on Precision Dairy Management, Toronto, 2-5 Mart, 2010.

[2] D. Weststeyn, Activity and rumination monitoring for calving times, Lisans Tezi, California Polytechnic State University, Dairy Science Department, 2011.

[3] W. Steeneveld, H. Hogeveen, "Characterization of Dutch Dairy Farms Using Sensor Systems for Cow Management", Journal of Dairy Science, 98(1), 709-717, 2015.

[4] E. Lindgren, Validation of rumination measurement equipmen and the role of rumination in dairy cow time budgets, Yüksek Lisans Tezi, Swedish University of Agricultural Sciences, Department of Animal Nutrition and Management, 2009.

[5] K. Hendriksen, W. Büscher, S. Hoppe, C. Hoffmanns, "Validation of An Acoustic Rumination Sensor for Dairy Cows", Internationa Conference of Agricultural Engineering, Zurich, 1-5, 6-10 Temmuz, 2014

[6] S. Büchel, Sensor-based control of chewing and rumination behavior of dairy cows, Doktora Tezi, University of Kassel, Faculty of Organic Agricultural Sciences, Department of Animal Nutrition and Animal Health, 2013.

[7] R. Firk, E. Stammer, W. Junge, J. Krieter, "Automation of Oestrus Detection in Dairy Cows: A Review", Livestock Production Science, 75(3), 219-232, 2002.

[8] N. Soriani, E. Trevisi, L. Calamari, "Relationships Between Rumination Time, Metabolic Conditions, and Health Status in Dairy Cows During the Transition Period", Journal of Animal Science, 90(12) 4544-4554, 2012
[9] P. J. Kononoff, , H. A. Lehman, A. J. Heinrichs, "Technical NoteA Comparison of Methods Used to Measure Eating and Ruminating Activity in Confined Dairy Cattle", Journal of dairy science, 85(7), 1801-1803, 2002

[10] C. Pahl, A. Haeussermann, K. M. Nerge, A. Grothmann, E. Hartung, "Comparison of Rumination Activity Records of Pressure Sensors and Acoustic Sensors", Proceedings of the International Conference on Agriculture Engineering, Valencia, 3, 1-6, 8-12 Temmuz, 2012

[11] B. Najafi, K. Akimian, A. Ionescu, F. Loew, C. J. Bula, P. Robert, "Ambulatory System for Human Motion Analysis Using a Kinematic Sensor: Monitoring of Daily Physical Activity in the Elderly", IEEE Transactions on Biomedical Engineering, 50(6), 711-723, 2003.

[12] D. C. Ranasinghe, R. L. S. Torres, K. Hill, R. Visvanathan, "Low Cost and Batteryless Sensor-enabled RFID Tag Based Approaches to Identify Patient Bed Entry and Exit Posture Transitions", Gait \& Posture, 39(1), 118-123, 2014

[13] R. L. S. Torres, D. C. Ranasinghe, A. P. Sample, "Sensor enabled wearable RFID technology for mitigating the Risk of Falls Near Beds", IEEE International Conference on RFID, Penang, 191-198, 30 Nisan - 2 Mayıs, 2013.

[14] A. Godfrey, A. K. Bourke, G. M. Olaighin, P. Ven, J. Nelson, "Activity Classification Using a Single Chest Mounted Tri-axial Accelerometer", Medical Engineering \& Physics, 33(9), 1127-1135, 2011.

[15] A. Hendriyawan, R. D. Mohd, "3D Image Construction Using Single LRF Hokuyo URG-04LX", Proceedings of Colloquium on Robotics, Unmanned Systems and Cybernetics, Pahang, 76-79, Kasım 2014 . 